\title{
O PROCESSO DE MONSTRIFICAÇÃO COMO METÁFORA DO MAL NOS MITOS DE METAMORFOSE
}

\author{
Natasha de Queiroz ALMEIDA ${ }^{1}$ \\ Maria do Perpétuo Socorro Galvão SIMÕES ${ }^{2}$
}

\begin{abstract}
RESUMO
As mitologias registram narrativas regidas pelo tema da metamorfose. Entretanto, as metamorfoses analisadas dentre narrativas do imaginário grego clássico e as narrativas do imaginário amazônico paraense expõem punições, restrições, bem como questões morais, geralmente resultantes de malefícios e transtornos sofridos pelos sujeitos que passam pelo processo físico da metamorfose. O objetivo deste estudo é estabelecer, numa abordagem comparativa, as relações entre a metamorfose do episódio da Antiguidade Clássica registrado no canto X, da Odisseia (VIEIRA, 2011) e a narrativa de metamorfose relatada no bairro do Jurunas (1994), a partir da figura do monstro, enquanto agente causador/sofredor do mal. Será realizado um levantamento bibliográfico sobre o caso de metamorfose como símbolo do mal na Odisseia, cuja tradução é de Trajano Vieira (2011) e sobre o caso de metamorfoses relatadas em narrativas orais de Belém, catalogadas e salvaguardadas no acervo IFNOPAP, em 1994 (O imaginário das formas narrativas orais da Amazônia paraense). A análise comparada versou sobre: Como o mal é representado na figura do monstro? Como os casos de metamorfoses apontam para questões de cunho sociomoralizante? Que motivações gerem cada um dos processos metamórficos? Os metamorfoseados ou monstros representam que tipo de homem? Observou-se que em ambos os episódios, as metamorfoses apresentaram questões de fundo moralizante e algum efeito nocivo ao agente metamorfoseado, sendo estas consequências derivações do mal causado, mal este entendido aqui como o sofrimento sentido pelo sujeito metamorfoseado por sua condição de abjeto, de objeto ou de privado de expressão. Além disso, por serem desdobramentos míticos, nos casos analisados jazem parâmetros de afinidades e de concorrência que: 1) mostram o quanto as narrativas de caráter mítico podem se reatualizar incessantemente pela palavra; 2) ilustram bem como as sociedades estão ordenadas e regidas por forças hierárquicas, quer sejam representadas por uma ordem natural humana, quer seja via uma ordem sobrenatural; 3) aproximam os homens de culturas diversas pelos interesses, comportamentos, buscas e receios. Assim, o estudo dos mitos de metamorfoses elucida bem a relação homem-mundo-sociedade, principalmente porque aponta para o 'momento de trânsito em que nos encontramos em que espaço e tempo se cruzam para produzir figuras complexas de diferença e identidade, passado e presente, interior e exterior, inclusão e exclusão' (BHABHA, 1998).
\end{abstract}

Palavras-chave: Monstro. Metamorfose. Mal. Narrativa.

\begin{abstract}
\end{abstract}
Mythologies record narratives governed by the theme of metamorphosis. However, the metamorphoses analyzed between narratives of the classical Greek imaginary and the narratives of the Amazonian imaginary of Pará expose punishments, restrictions, as well as moral issues, usually resulting from the harms and disorders suffered by the subjects who undergo the physical process of metamorphosis. The objective of this study is to establish, in a comparative approach, the relations between the metamorphosis of the episode of Classical Antiquity recorded in corner X of the Odyssey (VIEIRA, 2011) and the narrative of metamorphosis reported in the neighborhood of Jurunas (1994), from figure of the monster, as causer / sufferer of evil. The bibliographical survey on the case of metamorphosis as a symbol of evil in Odyssey, translated by Trajano Vieira (2011) and on the case of metamorphoses reported in oral narratives of Belém, cataloged and safeguarded in the IFNOPAP collection, in 1994 (O of the oral narrative
2 Doutora em Letras (Letras Vernáculas) pela Universidade Federal do Rio de Janeiro. É professora da Universidade Federal do Pará, coordenadora do Programa de Estudos Geo-BioCulturais da Ama- zônia - Campus Flutuante, da Universidade Federal do Pará. E-mail: galvao@ufpa. com.

VOL. 14 | N. 1 | JUN. 2017 
forms of the Paraense Amazon). The comparative analysis dealt with: How is evil represented in the figure of the monster? How do the cases of metamorphoses point to issues of a socio-moral character? What motivates each of the metamorphic processes? Do the metamorphosed or monsters represent what kind of man? It was observed that in both episodes, the metamorphoses presented questions of moralizing background and some harmful effect to the agent metamorphosed, being these consequences derivations of the evil caused, badly understood here as the suffering felt by the subject metamorphosed by its condition of abject, of object or of private expression. Moreover, because they are mythical unfoldings, in the analyzed cases lie parameters of affinities and competition that: 1) show how mythical narratives can be incessantly reanalyzed by the word; 2) illustrate how societies are ordered and ruled by hierarchical forces, whether represented by a natural human order or via a supernatural order; 3 ) bring men together from diverse cultures by interests, behaviors, pursuits and fears. Thus, the study of the myths of metamorphoses elucidates the human-world-society relation, mainly because it points to the moment of transit in which we find ourselves in which space and time intersect to produce complex figures of difference and identity, past and present , interior and exterior, inclusion and exclusion '(BHABHA, 1998).

Keywords: Monster.Metamorphosy. Evil. Narrative

\section{INTRODUÇÃO}

3 O projeto IFNOPAP reúne, hoje, um acervo de mais de 5000 narrativas orais populares da Amazônia Paraense. Entre 1994 e 2004, a pesquisa IFNOPAP foi realizada, no Estado do Pará, atingindo 98 municípios, com a participação de cerca de 200 contadores de mais de 5300 histórias. Os dados levam à constatação de que se trata de um dos maiores acervos orais do mundo acadêmico, no gênero. Hoje, as narrativas digitalizadas transcritas totalizam 1.439 , visto que parte do acervo originalmente coletado em áudio foi irremediavelmente prejudicada pelas condições climáticas da região, configurando-se a perda de parte deste material. $\mathrm{O}$ acervo também conta com um banco de dados composto de narrativas em áudio que contabilizam cerca de 1.400 narrativas. As narrativas retiradas deste acervo e analisadas neste artigo são de origem unicamente da região metropolitana de Belém. Em pesquisa anterior, constatou-se que $20 \%$ das narrativas catalogadas no campus de Belém conformam o tema da metamorfose. E é a este corpus especifico que se atém este trabalho.
Os casos de metamorfoses afloram em diversas mitologias como um processo de transformação física gerido por transtornos e sofrimentos tão marcantes que o agente-sujeito do processo é, geralmente, descrito como um monstro que, por sua vez, causa ou apenas sofre o mal. Para ilustrar isso, serão analisadas no presente artigo duas narrativas que tocam no tema mitológico da metamorfose.

A primeira narrativa apresentada presente no canto $X$, da Odisseia, registra o episódio em que a feiticeira Circe, com seus ardis, aprisiona os homens do herói Ulisses e os transforma em porcos. Mesmo com a imprecisão quanto à data da escritura do texto homérico da Odisseia, a partir da Antiguidade Clássica, estudos sobre Homero, realizados pelo pesquisador americano Milman Parry, fundador de um centro de pesquisa em oralidade na Universidade de Harvard, onde se encontra a Coleção de Literatura Oral recolhida por ele, demonstrou cientificamente que métodos estilísticos usados pelo autor da Ilíada e Odisseia eram usados na oralidade e suas conclusões vêm reforçar a tese de que "a composição das epopeias homéricas ocorreu muito antes do difundido uso da escrita na Grécia" (SCHOLES \& KELLOGG, 1977, p.13). Para isso, Milman Parry levantou e estudou elementos tradicionais da dicção homérica a que ele denominou de "fórmulas", definidas como "um grupo de palavras regularmente empregado sob as mesmas condições métricas para expressar uma determinada ideia essencial" (SCHOLES \& KELLOGG, 1977, p.13). Segundo sua ótica, uma dicção poética altamente formular é prova de composição oral, uma vez que os poetas populares compõem mediante "fórmulas".

Entretanto, a escrita tem registrado o que outrora era fruto apenas do oral. O registro torna-se fundamentalmente importante diante da necessidade de perpetuar por gerações produções textuais, sem que se corra o risco tão imanente de se perder informações de cunho etnográfico, literário, cultural, histórico, geográfico e sociológico de comunidades de outrora. Graças a este tipo de registro não-abstrato, as gerações contemporâneas podem ter acesso, por exemplo, a Ilíada e a Odisseia de Homero, enquanto obras literárias e que tem atravessado séculos e gerações de estudo nas mais variadas áreas de conhecimento.

A segunda narrativa catalogada no acervo IFNOPAP ${ }^{3}$ é o registro também escrito de uma contação inventariada no bairro do Jurunas, em 1994, que versa sobre um homem citadino que também se transforma em porco ao cair da noite, e se envolve em um incidente que o leva a delegacia. Ambas as narrativas, frutos de uma Literatura Oral por tradição, assumem nesta escritura o status de documento, pois já disse Luis Costa Lima: 
um instrumento que comprova a existência prévia de algo outro. [...] Segundo uma aproximação retificadora, dir-se-ia que esse algo comprovado pelo documento possui tal ordem de existência que esta existência se repete, se refaz e se reatualiza por efeito de sua prova. $O$ documento então representaria $o$ que teria plena existência antes dele e sem ele (LIMA, 1986, p. 197).

Mesmo estas narrativas estando separadas pelo tempo e pelo espaço nos quais foram produzidas, uma comprova a experiência prévia da outra, pois o que se contou de alguma forma 'se repetiu, se refez e se reatualizou' em outro espaço e em outro tempo. Neste sentido, é bem apropriada a abordagem comparativa das duas produções literárias em questão, pois

o objeto tem de ser duplo, constituido que é por obras literárias geradas em contextos nacionais diferentes que são, no entanto, analisadas contrastivamente com o fim de ampliar tanto o horizonte limitado do conhecimento artístico, quanto a visão crítica das literaturas nacionais (SANTIAGO, 1982, p. 19).

Desta feita, o presente estudo visa não somente evidenciar as correlações e diferenças entra as metamorfoses do corpus narratológico, mas objetiva estabelecer as relações entre a metamorfose do episódio homérico grego e a metamorfose relatada que constitui o imaginário da Amazônia paraense, a partir da figura do monstro, enquanto agente causador/sofredor do mal. A partir destas narrativas, pretende-se verificar: Como o mal é representado na figura do monstro? Como os casos de metamorfoses apontam para questões de cunho sócio-moralizante? Que motivações gerem cada um dos processos metamórficos? Os metamorfoseados ou monstros representam que tipo de homem?

\section{OS MONTROS E O MAL NAS METAMORFOSES}

Clamando a Mnemosine, quem não se lembra da famosa narrativa bíblica em que seres celestiais, superiores aos humanos, passaram a desejar ardentemente, desde os céus, as mulheres da terra e a tomar seus corpos sexualmente? Porém, como fariam isso se seus corpos não eram terrenos? Ao se considerar os mitos gregos, é interessante ver como a Bíblia explica este mito pelo tema da metamorfose:

Ora, sucedeu que, quando os homens principiaram a aumentar em número na superficie do solo e lhes nasceram filhas, então os filhos do [verdadeiro] Deus começaram a notar as filhas dos homens, que elas eram bem-parecidas; e foram tomar para si esposas, a saber, todas as que escolheram. [...] Naqueles dias veio a haver os nefilins na terra, e também depois, quando os filhos do [verdadeiro] Deus continuaram a ter relações com as filhas dos homens e elas lhes deram filhos; eles eram os poderosos da antiguidade, os homens de fama. (BÍBLIA. Português. Tradução do Novo Mundo das escrituras Sagradas, 1986, p. 22)

Conforme mostra o relato do livro bíblico de Gênesis, em tempos pré-diluvianos, filhos angélicos de Deus vieram a terra, evidentemente materializando-se em forma humana, e coabitaram com mulheres atraentes. Produziram descendentes chamados de nefilins, que em hebraico significa derrubador, isto é, "os que fazem outros cair" (BÍBLIA. Português. Tradução do Novo Mundo das escrituras Sagradas, 1986, p. 22). O resultado desta união, tida como desnatural, de criaturas espirituais 
com humanos, é explicada pela geração de uma raça híbrida de homens carnais, mas com força sobrenatural. Estes descendentes são descritos como verdadeiros monstros, pois de acordo com Julio Jeha "nas mais antigas e diversas mitologias, o monstro aparece como símbolo da relação de estranheza entre nós e o mundo que cerca" (JEHA, 2007. p.7).

Somente a partir da metamorfose de um de seus progenitores, é que foi possível o nascimento desta extinta raça híbrida de humanos, descrita pelo mito, capaz de subjugar os humanos naturais.

Este relato bíblico retrata os descendentes de metamorfoseados sob uma luz desfavorável, posto que o contexto referenda que estes homens foram extirpados da face da terra por meio do dilúvio:

Depois Deus disse a Noé: "Chegou o fim de toda a carne diante de mim, porque a terra está cheia de violência por causa deles [dos nefilins]; e eis que os arruíno juntamente com a terra. (BÍBLIA. Português. Tradução do Novo Mundo das escrituras Sagradas, 1986, p. 22)

Por serem considerados "anormais", estes homens rotulados como violentos, aos olhos do Ser Supremo, precisariam ser eliminados da humanidade vivente. Entendimento este bastante condizente com o conceito de monstro para Agostinho, pois,

Para Agostinho, "monstro" significava um afastamento pessoal de Deus, e só era aplicado a individuos considerados "anormais". A literatura da Renascença descreve pecados especificos (ciúme, orgulho, etc.) como monstruosos. Nesse caso, "monstruosidade" carrega implicações tanto estéticas quanto políticas (JEHA, 2007, p. 7).

Tanto mais os metamorfoseados, responsáveis por uma geração inteira de nefilins, encontravam-se numa condição apartada de Deus, por abandonarem seus corpos e domínios originais, a fim de ter relações com mulheres terrenas. Desta forma, seus descendentes não poderiam fugir de um julgamento desfavorável tanto estética, quanto politicamente, além do que a manutenção de seu poder estava baseada na violência. Um juízo adverso esteve condicionado, neste relato, a um comportamento beligerante e imoral, por assim dizer. Eis um índice de motivação moral na narrativa. Similarmente, outras mitologias salvaguardam muitas metamorfoses que metaforizam o mal de maneiras diversas. Mas, como traçar os rastros da marcante presença do mal nas narrativas de metamorfoses aqui abordadas? Paul Ricouer diz que é possível torná-lo visível por meio de mitos e de símbolos, mesmo não sendo estes totalmente capazes de representá-lo em sua inteireza.

A exemplo da mitologia grega, a narrativa homérica da Odisseia, no canto $\mathrm{X}$, registra o momento em que a mítica Circe transforma os companheiros de Ulisses em porcos, sendo estes monstrificados aqui pelo fato de adquirirem corpos completamente incomuns a humanos, estando numa condição de "anormalidade" em relação a sua forma original, causando profunda estranheza, e que só retomam a forma humana por intermédio da intervenção do herói.

Ela não tardou a sair; abriu as luzidias portas e convidou-os. Todo grupo, em sua ignorância, segui-a; [...] Ela os fez entrar e sentar em divãs e cadeiras; preparou-lhes uma papa de queijo, cevada e pálido mel, com vinho de Pramnos; nessa comida misturou drogas daninhas, para tirar-lhes toda lembrança da terra pátria. Assim que lha serviu e eles a sorveram, bateu-lhes com a vara de condão e fechou-os em pocilgas. Tinham agora cabeça, voz, cerdas e corpos de suínos, embora conservassem 
a inteligência como antes [...] (HOMERO, 1994, p. 118).

Observa-se nesse caso o conceito de metamorfose bem latente: não se trata de uma transformação ou passagem integral e irrevogável de um estado a outro ${ }^{4}$, ao contrário, trata-se de uma mudança física passageira e não total, pois a passagem acima revela que, por meio de um elemento mágico, apenas a anatomia dos companheiros de Ulisses sofreu a transformação para corpos de suínos, e não tiveram suas faculdades cognitivas alteradas, visto que 'conservaram a inteligência como antes'. Tais modificações na forma não pareceram afetar as personalidades profundas, que em geral guardam o seu nome e seu psiquismo. De todo modo,

essas metamorfoses podem ter aspecto negativo ou positivo, dependendo de se elas representem uma recompensa ou um castigo e de acordo com as finalidades às quais obedeçam (CHEVALIER, J. \& GHEERBRANT, 2009, p. 608).

Na narrativa homérica, o cunho foi punitivo, visto que os homens de Ulisses não tiveram discernimento sobre as verdadeiras intenções de Circe, nos seus planos de deixar a todos sem "lembrança da terra pátria"; mostraram-se, portanto, ignorantes ao segui-la cegamente para a ardilosa refeição. O caráter punitivo e provador da cilada de Circe jaz no fato de que os homens de Ulisses estavam conscientes da mudança humilhante que ocorria em seus corpos físicos, pois, conforme o relato, não perderam a inteligência, isto é, suas faculdades cognitivas e sensoriais permaneceram intactas, a fim de que estivessem bem apercebidos do que lhes acontecia e impotentes em sua condição. Ironicamente, Circe os transforma em porcos, animal este que, em muitas culturas, é símbolo das tendências obscuras, sob todas as suas formas, da ignorância, da gula, da luxúria e do egoísmo (CHEVALIER, J. \& GHEERBRANT, 2009, p. 734). Comilões, os vorazes companheiros de Ulisses, viajantes de uma longa jornada, atenderam às suas necessidades mais primitivas, sem ponderar as finalidades da feiticeira por detrás daquele banquete, mostrando-se, portanto, estúpidos. Se fossem sagazes e perspicazes não teriam se desfeito nos prazeres da carne sedenta naquele banquete, e consequentemente, não virariam porcos. Este parece ser o mal mais enfatizado pela narrativa grega: o de serem rebaixados pelo uso de suas inteligências, a partir das metamorfoses induzidas por Circe.

Outro malefício identificado nessa narrativa diz respeito às referências a uma condição abjetal, na qual se encontravam os companheiros de Ulisses, uma condição repulsiva, pois foram subjugados pelos efeitos dos poderes de Circe e afastados ou diferenciados, por exemplo, de Ulisses, o herói, continuamente humano, que não se deixou levar por seus impulsos. Estas circunstâncias constituem a cena viva do que Julia Kristeva considera a dinâmica da abjeção: "Não é a falta de limpeza ou saúde que causa abjeção, mas o que perturba a identidade, o sistema, a ordem. O que não respeita limites, posições, regras. O 'entre-dois', o ambíguo, o compósito" (KRISTEVA, 1982. p.4). Ou seja, primordialmente, os homens animalizados não são repulsivos por terem esteticamente a forma física de suínos; são considerados desprezíveis por uma questão moralística, pois não foram capazes de respeitar seus próprios limites diante do banquete-armadilha, perturbando com isso sua própria identidade, pois mesmo tendo corpos de porcos, seus psiquismos foram conservados. Estavam cônscios de seu erro e de sua incapacidade de: a) não conter suas vontades "incontroláveis"; b) não poder agir para retornar a sua forma humana anterior, pois estavam sujeitos a vontade das artes mágicas da feiticeira.

Entretanto, a citação acima da Odisseia é bastante ilustrativa, pois, diante dos inúmeros significados que a narrativa grega permite inferir, destaca-se aqui, sobretudo, o seguinte: Sendo os próprios companheiros de Ulisses que aceitaram e se apressaram para o banquete, não teria Circe com sua armadilha apenas exposto os anseios e as pretensões destes homens? Trata-se aqui da abjeção não do corpo metamorfoseado, e sim da obstrução do eu do sujeito pelo seu próprio comportamento e pela subjugação social do homem (DIAS, 2007. p. 27). Isso é notório na figura
4 Com o fim de maiores esclarecimentos, "os fenômenos da metamorfose passageira devem ser nitidamente diferenciados dos da metempsicose propriamente dita, que é uma transmigração, uma passagem total e definitiva de um estado para outro." (in CHEVALIER, Jean, GHEERBRANT, Alain. Dicionário de símbolos: mitos, sonhos, costumes, gestos, formas, figuras, cores, números. Trad. Vera da Costa e Silva. $23^{\mathrm{a}}$ ed. Rio de Janeiro: José Olympio, 2009. p. 608, grifos nossos). 
salvadora de Ulisses, que enquanto humano e sábio, no que concerne ao uso salutar de suas faculdades cognitivas, foi capaz de salvar os homens animalizados.

Portanto, cabe aqui a reflexão realizada por Homi Bhabha (1998) na formação deste sujeito nos "entre-lugares", que é destacadamente válido para o metamorfoseado por estar em uma condição sempre limite:

De que modo chegam a ser formuladas estratégias de representação ou aquisição de poder no interior das pretensões concorrentes de comunidades em que, apesar de histórias comuns de privação e discriminação, o intercâmbio de valores, significados e prioridades pode nem sempre ser colaborativo e dialógico, podendo ser profundamente antagônico, conflituoso e até incomensurável? (BHABHA, 1998, p. 20).

No caso da narrativa acima mencionada, o mito da metamorfose serviria como uma explicação, caso os companheiros de Ulisses não conseguissem retornar à sua terra pela falta da lembrança de sua terra natal, conforme intencionava a feiticeira, bem como desmoraliza os homens de Odisseu por não terem tido discernimento diante da armadilha, exaltando a figura do herói.

Porém, uma representação ainda mais latente é aquela que versa sobre o mal no processo de monstrificação da narrativa. Na narrativa homérica, "o mal é cometido, mas também é sofrido, e, como sofrimento, é a essência dos seres vivos. [...] O sofrimento afunda o mundo, nos embrutece, nos priva da capacidade de expressão, nos torna meros objetos, detritos numa terra devastada" (JEHA, 2007, p. 9). O sofrimento gerado aos homens de Ulisses é comum a todos aqueles que se sentem presos a uma condição de privação de expressão, seja esta de qualquer sorte, diante da desagradável e desconfortável sujeição a que foram destinados.

Analogicamente, este sofrimento por um mal que gera a impossibilidade de mudança diante de uma situação desagradável também é recorrentemente ilustrado em narrativas orais oriundas de contadores da Amazônia paraense, que também conformam estas condições desagradáveis no processo de monstrificação das metamorfoses. Ademais, que diálogo a narrativa grega estabelece com as narrativas orais da Amazônia paraense? Que representações em ambas as narrativas são intercambiais e/ou conflituosas?

O acervo IFNOPAP registra muitas contações que versam especificamente sobre pessoas que são transformadas em porcos, geralmente, metamorfoses estas advindas de alguma transgressão fatalmente hereditária ou com nenhuma explicação mencionada, mas que se perpetua interminavelmente ou temporariamente por ação de caráter mágico, tal como a feiticeira Circe efetuou. Na narrativa intitulada Amâncio, o porco (Narrativa retirada do acervo IFNOPAP, código de localização KN02CZjur190994-III.), por exemplo, o enredo versa sobre um homem trabalhador braçal de um frigorífico que é revelado pelos mistérios da noite como alguém que sofre metamorfose:

\author{
Amâncio, o porco \\ "como é que tu tens coragem de batê, \\ na cabeça do seu Amâncio?"
}

Essa história do porco é uma história conhecida, dos antigos moradores do Jurunas

Quem contou né, foi minha avó, ela conta o seguinte:

Que no [Jurunas] ela trabalhava com um [marchante] num supermercado de carne, então tinha um tal de Zé Carlos lá, que ele trabalhava com um carregador de carne que chegava lá, nos frigorificos, ai diziam que ele se transformava em porco. Quando foi uma vez, uma madrugada, o meu avô ele vinha 
pela rua de Pariquis, também é antiga ainda tinha bonde, ele passou pela prefeitura... prefeitura não desculpa, pela delegacia de policia, policial do Jurunas aquela época, e um porco saiu dentro do mato, dos matagais avançou nele, um porco bem feroz mesmo, aí ele pega, um pau na hora, uma estaca, bate no porco na cabeça do porco, abri uma brecha o porco sai gritando, por dentro do mato, volta, ao mato.

Quando foi pela parte da manhã, a policia, o delegado, o investigador foi lá na casa da minha avó, chegando lá batero, [policia dentro do bairro né?] conhecida no bairro, açougueira, uma mulhé no bairro açougueira é conhecidíssima, e meu avó também que ele era oficial de justiça, o investigador chegou lá com o delegado e....disse pra minha avó:

_Dona Lisia, seu Benedito tá aí? Gostaria de falá com ele um instantinho!

_Olha ele tá dormindo, tá de folga hoje, o que era?

Não é um assunto, a senhora vai ouvi o eu é?

Aífoi, ai se acordou, tudo, ai disse pro investigador, do que era que se tratava, ai o delegado disse pra ele:

_Mas Benedito, como é que tu tens coragem de batê, na cabeça $\bar{d}$ o seu Amâncio?

Aí meu avó, ficou surpreso, com aquilo sabe?

Eu bati no seu Amâncio! Jamais, seu Amâncio é um senhor que ajuda minha esposa, [com descarregamento de carne] por quê eu ia batê nele, meu amigo, amigo da minha esposa. Que história é essa?

_Olha Benedito, ele [tá alegando], ele foi na delegacia, alegando que foi de madrugada, que tu encontrasse com ele, ele tava porre te pedindo dinheiro, tu desse umas tacada na cabeça dele!

Ele disse:

_Olha delegado, tu não vai acreditá no que eu vou te contá, mas a única coisa, que eu dei umas tacada na cabeça, foi de um porco, então todo mundo diz que ele vira porco, agora eu num quero crê, no que eu dei, fosse um porco realmente, [encantado???].

Então ficou esclarecido, né? Ele tava realmente com uma brecha na cabeça, sabe? Então até hoje, o pessoal dizem que ele virava porco.

O tema da metamorfose é trabalhado no texto desde seu início como algo natural dentro de sua peculiaridade, pois para além do fato de ser uma história recorrente no bairro belenense do Jurunas, o próprio personagem, o senhor Amâncio, recorre a outros personagens marcadores de um espaço extremamente citadino e que revela outra relação social, diferente da estabelecida na Grécia clássica, tornando a narrativa altamente reatualizada conforme a vivência de quem narra: o elo entre o policial, o investigador e o delegado.

Trata-se, antes de qualquer coisa, de um cidadão (civita) atento ao cumprimento de seus direitos na polis, pois até o homem que virava porco exigiu a chamada de seus direitos sobre um ato que considerou uma violência ao seu corpo metamorfoseado, recaindo no tripé que norteia a construção do conceito de cidade: a política, qual arte do convívio; a polícia, enquanto zeladora da vigilância dos costumes e comportamentos; e politesse, como a atmosfera de sociabilidade, polidez e decoro (PECHMAN, 1997, p.21). O senhor Amâncio reivindicou a mantenedora ordem deste tripé da cidade, por mais incomum que se mostrassem os efeitos da metamorfose de seu corpo.

Contudo, nosso personagem não parece constrangido e muito menos satis- VOL. $14 \mid$ N. $1 \mid$ JUN. 2017 
feito por revelar à polícia a agressão que sofreu, mesmo correndo o risco de ter seu segredo sobre a metamorfose revelado, como sucedeu. Antes, via sua transformação como algo natural e que era uma extensão de seu corpo humano, por isso entendeu como uma agressão a ação inadvertida de seu conhecido, fazendo com que ele procurasse ainda assim seus direitos como cidadão. Neste caso, bem apropriada é a reflexão feita por Jeha sobre "o que é, então, o mal? Devemos transferi-lo do nosso lado impuro, para o nosso lado puro, transformando-o em sofrimento" (JEHA, 2007, p.11). Este foi o exercício realizado pelo senhor Amâncio, pois a violência sofrida quando estava transformado no lado impuro de seu corpo metamorfoseado e alcovitado pelos mistérios da noite, foi reivindicada com pesar pelo seu lado puro, humano. Logo, o que é a própria representação do mal, neste caso, não é diretamente o corpo que foi transformado e punido pela metamorfose, antes é aqui significado pela circunstante violência sofrida pelo porco, independentemente deste animal ter caráter animalia nato, por ser um porco naturalmente ou estar na condição de porco e ter caráter humanóide, situação última oportunizada pelo acontecimento da metamorfose. O mal está presente na violência que sofreu por ter sido espancado por um homem com um pedaço de madeira: $O$ senhor Amâncio foi vítima de violência, o que independe, na narrativa, de seu estado físico. Assim, a narrativa iguala ou nivela a violência sofrida por um homem e/ou aquela sofrida por um animal, tendo o ato o mesmo peso e a mesma medida para o agente vitimado.

O episódio homérico de Circe ainda mostra o homem à mercê do poder dos deuses e que só se torna livrado de algum efeito danoso, caso apele a outros deuses ou à sua própria sapiência diante de uma situação-limite, atitude nobre esta que consagra a imagem do herói. Observa-se, portanto, que leis diferenciadas regem as relações dos homens através dos tempos, e que um mesmo tema mítico assume a cor local na cronologia, a partir do estabelecimento de relações sociais outras.

Em relação à ação da metamorfose em si sobre o corpo do senhor Amâncio, algo semelhante aconteceu no episódio homérico entre Circe e os tripulantes: ambos não perderam a consciência, nem suas faculdades cognitivas por ocasião da metamorfose. Isso se comprova pelo fato do senhor Amâncio, com propriedade, registrar sua queixa, formalmente, na delegacia sobre a violência de que fora vítima, cuidando, inclusive de ocultar e mentir um dado fundamental na ocorrência: o de que era um porco e não estava bêbado, como falou às autoridades.

O homem só foi revelado porco pela coincidência de versões sobre a mesma história, que pareceu complementar-se.

O senhor Amâncio é a representação do homem em um novo senso, em uma nova relação de si mesmo com a natureza. Ele procura reconciliar o exercício da humanidade à sua natureza animália no devir da transformação; fala-se aqui de um "homem ressensualizado" no sentido de que este reencontra e reconcilia na narrativa sua consciência em relação às coisas.

Tanto Ulisses, que não sofreu a metamorfose, mas que se viu envolvido no embate da transformação de seus tripulantes, quanto Amâncio que sofreu metamorfose, trataram de reincorporar a dimensão da afetividade no pensamento, pois quando diante do processo de mutação cada um, ao seu modo, procurou vencer um estado não natural pela racionalidade. Entretanto, a vitória da razão (dotada de uma racionalidade que funciona sobre regras de ferro, isto é, pelo constrangimento, pela força, tal qual o pensamento mítico) sobre o mito representa a tarefa histórica de deixar os instintos sob o controle do tribunal competente da razão instrumental, ou melhor, da razão dominadora: Amâncio, quando homem, buscou meios jurídicos para reivindicar seus direitos, mesmo que tenha sofrido a transgressão quando era ou estava porco; e Ulisses, por ser o único apto física e cognitivamente para desfazer os efeitos subjugadores da metamorfose em seus companheiros.

De toda forma, ambos os casos de metamorfose mitos confirmam o que Theodor Adorno e Max Horkheimer refletem sobre a existência dos homens como seres que projetam os mitos para atender aos seus questionamentos pessoais e universais, mas que ao mesmo tempo, 
sempre tiveram de escolher entre submeter-se à natureza ou submeter a natureza ao eu. [...] Forçado pela dominação, o trabalho humano tendeu sempre a se afastar do mito, voltando a cair sob o seu influxo, levado pela dominação (ADORNO, 1985, p. 43).

Diante do mal, Ulisses e Amâncio reagiram em cumprimento ao conceito de sabedoria atinada quando diante de um perigo colocado por Jeha, como aquela que "nos caracteriza como respondendo inadvertidamente a ameaças a nossa auto-identidade" (JEHA, 2007, p. 13).

Sim, o aplicativo da racionalidade diante do mal catalisa a explicação das metamorfoses dentre as diversas mitologias, incluindo aqui o imaginário grego e o amazônico.

\section{CONSIDERAÇÕES FINAIS}

O presente artigo mapeou as representações do monstro, enquanto agente-sujeito do mal, nos casos míticos de metamorfoses recorrentes na Antiguidade Clássica grega e na narrativa oral relatada em Belém, no bairro do Jurunas, no final do século XX. Observou-se que em ambos os episódios, as metamorfoses apresentaram questões de fundo moralizante e algum efeito nocivo ao agente metamorfoseado, sendo estas conseqüências derivações do mal causado, mal este entendido aqui como o sofrimento sentido pelo sujeito metamorfoseado por sua condição de abjeto, de objeto ou de privado de expressão.

Além disso, por serem desdobramentos míticos, nos casos aqui analisados jazem parâmetros de afinidades e de concorrência que: 1) mostram o quanto as narrativas de caráter mítico podem se reatualizar incessantemente pela palavra; 2) ilustram bem como as sociedades estão ordenadas e regidas por forças hierárquicas, quer sejam representadas por uma ordem natural humana, quer seja via uma ordem sobrenatural; 3) aproximam os homens de culturas diversas pelos interesses, comportamentos, buscas e receios. Os aspectos afins e concorrentes das narrativas de valor mítico, em meio ao prazer provocado por um relato totalmente humano, são articulados em qualquer instância cultural conforme um conjunto de regras que,

para uma determinada cultura, são rigorosas. Esse código comanda e orienta o jogo da imaginação mítica; delimita e organiza o campo no qual ela pode se produzir, modificar os velhos esquemas, elaborar novas versões; é tirando proveito dos limites que impõe bem como das compatibilidades que permite, explorando a gama das direções abertas, que se efetua o trabalho de invenção e que, pela retomada contínua da tradição, um pensamento mítico, em uma civilização, permanece vivo (VERNANT, 2001, p. 232).

Além de tentar explorar as (in)compatibilidades e o jogo de imaginação mítica nas narrativas, o presente artigo apontou para a necessidade que temos de que "como criaturas literárias e animais políticos, devemos nos preocupar com a compreensão da ação humana e do mundo social como um momento em que algo está fora do controle, mas não fora da possibilidade de organização" (BHABHA, 1998, p. 34). E o estudo dos mitos de metamorfoses elucida bem a relação homem-mundo-sociedade, principalmente porque aponta para o 'momento de trânsito em que nos encontramos em que espaço e tempo se cruzam para produzir figuras complexas de diferença e identidade, passado e presente, interior e exterior, inclusão e exclusão'(BHABHA, 1998, p. 19). 


\section{REFERÊNCIAS}

ADORNO, Theodor, HORKHEIMER, Max. Dialética do Esclarecimento: fragmentos filosóficos. 2 ed. Tradução Guido Antonio de Almeida. Rio de Janeiro: Zahar, 1985.

BHABHA, Homi. "Locais da cultura". In: O local da cultura. Belo Horizonte: UFMG, 1998.

BÍBLIA. Português. Tradução do Novo Mundo das escrituras Sagradas. Tradução da versão inglesa de 1961 mediante consulta constante ao antigo texto hebraico, aramaico e grego. Estados Unidos da América: Watchtower Bible and Tract Society of New York, INC, 1986.

CHEVALIER, Jean, GHEERBRANT, Alain. Dicionário de simbolos: mitos, sonhos, costumes, gestos, formas, figuras, cores, números. Trad. Vera da Costa e Silva. 23a ed. Rio de Janeiro: José Olympio, 2009.

DIAS, Angela Maria. O papel do abjeto na literatura contemporânea e a obra de André Sant'anna: Um estudo de caso. In: revista eletrônica do Instituto de Humanidades XXII. Vol VI. N XXII. 2007.

HOMERO. Odisseia. Tradução Jaime Bruna. São Paulo: Cultrix, 1994.

JEHA, Julio. Monstros e monstruosidades na literatura. Belo Horizonte: Editora UFMG, 2007.

KRISTEVA, Julia. Powers of Horror. An Essay on Abjection. Translated by Leon S. Roudiez.New York, Columbia University Press, 1982.

LIMA, Luis Costa. "Documento e Ficção". In: Sociedade e discurso ficcional. Rio de Janeiro: Guanabara, 1986.

PECHMAN, Robert. "Pedra, cidade e discurso: Cidade, História e Literatura". In: Gêneros de fronteira: cruzamentos entre o histórico e o literário. São Paulo. Xamã: 1997.

SANTIAGO, Silviano. "Apesar de dependente, universal”. In: Vale quanto pesa: ensaios sobre questões político-culturais. Rio de Janeiro: Paz e Terra, 1982.

SCHOLES, Robert \& KELLOGG, Robert. A natureza da narrativa. Rio de Janeiro: MCGrallHill, 1977.

VERNANT, Jean-Pierre. "A questão mitológica". In: Entre Mito e Política. Edusp. São Paulo: 2001. 